\title{
EXPLORING THE DIMENSIONS OF INNOVATION CULTURE IN THE PUBLIC HIGHER EDUCATION INSTITUTIONS: TOWARDS \\ IMPROVED ORGANIZATIONAL PERFORMANCE IN ReSEARCH AND DEVELOPMENT
}

\author{
Paul Jersey G. Leron* University of the Philippines, pgleron@up.edu.ph \\ Los Baños, College of Public \\ Affairs and Development, The \\ Philippines \\ Rowena D.T. University of the Philippines, rdbaconguis@up.edu.ph \\ Baconguis Los Baños, College of Public \\ Affairs and Development, The \\ Philippines \\ * Corresponding author
}

ABSTRACT

What is new?

This paper extends the concept of innovation culture in the context of public higher education institutions (HEIs) in the Philippines. There is a need to understand the concept and establish its applicability to public HEls, particularly its role in promoting research and development $(R \& D)$ performance in the organization.

What was the

Through a case study approach, a total of 40 individuals approach? composed of research and development (R\&D) managers and administrators, innovators, and faculty research personnel from four selected public HEls participated in the in-depth interviews and Focus Group Discussions (FGDs). Through synthesis of previous studies, we learned the different organizational, human, and collaborative dimensions of innovation culture, albeit in the context of private manufacturing organizations.

What is the academic Results revealed that the aspects of innovation and the concept impact? of innovation culture were embedded in the institutional statements as well as in the values of the participants. It was also found that innovation culture is a widely understood concept in terms of its attributes or building blocks. Through this study, we understood the importance of innovation culture in promoting performance amidst the challenges of doing R\&D 
What is the wider impact?

Keywords in public HEls. We learned that creativity and flexibility, innovation resources, training and capacity development, and coaching and mentoring were the key elements of innovation culture that can help address the managerial and institutional challenges in doing R\&D in academic organizations.

This study added the concept of innovation culture in the current analytical frameworks that explain engagements and productivity in terms of academic, scientific, and extension outputs of faculty-researchers in the university. In addition, identifying and determining the impacts of innovation culture on R\&D productivity in the local and international academic organizations were relevant research areas to explore in future studies.

innovation culture, academic organizations, higher education institutions, research and development

INTRODUCTION

Innovation culture is described in many ways. For Claver et al. (1998), innovation culture is described as "the way of thinking and behaving that creates, develops and establishes values and attitudes within an organization, which may in turn raise, accept and support ideas and changes involving an improvement in the functioning and efficiency of the organization, even though such changes may mean a conflict with conventional and traditional behavior". However, there exists a gap in the literature on innovation culture, which are mostly from management and business organization perspectives. There is a need to understand the concept and establish the applicability of innovation culture in the context of public higher education institutions (HEls), particularly its potential role in organizational research and development (R\&D) performance.

Several authors have defined innovation culture as a multidimensional context and constructs (Stock et al., 2013) yet it remains a frequently used concept. It is often regarded as a self-explanatory phenomenon and can be described by a somewhat universal set of characteristics. Innovation culture is an environment and a culture (Xie et al., 2016), which emphasizes participation and drives growth and performance (Tian et al., 2018). However, there remains the need for a consensus regarding its dimensions or determinants (Eynde et al., 2015 and Jucevicius, 2010). Some authors considered innovation culture as a dimension of organizational culture, referring specifically to attitudes towards innovation, technology, knowledge exchange, entrepreneurial activities and part of the major innovation capabilities (Anderson et al., 2012 and Alm \& Jonsson, 2014) and is made up of technological visions, research traditions, value systems etc., shared by those who take part in the innovation process (Jucevicius, 2010). 
A range of studies, which were commonly done in the context of private and manufacturing organizations, have presented similar, yet overlapping concepts and dimensions of innovation culture. Some were used to characterize an organization while others described what constitutes an innovative culture. Alm and Jönsson (2014) proposed five dimensions of innovation culture. These are innovation readiness, creativity and learning, leadership and entrepreneurship, market orientation, and motivations and relations. They also identified shared purpose, supportive leadership, willingness to dedicate resources, and an organization-wide customer focus as some of the success factors that influence culture of innovation in the organization. On the other hand, Roffeei et al. (2016 and 2018) proposed an innovation culture framework for understanding the university culture, environment, and member's approaches/actions and the factors that affect students' innovative behavior. Under the external environment are goals and motivation and communication while the internal environment captures the infrastructure, rewards and incentives, nature of work, teamwork, support, and interpersonal relations. Meanwhile, innovative culture is described through the stories, rituals, and language used in the university. These drive innovative behavior such as curiosity, creativity, flexibility, proactiveness, autonomy, empowerment, risk-taking, mistake-handling, and noveltyseeking. Schertlin (2018) provided other elements to be considered in assessing innovation culture: communication of the intention to innovate; incentives and rewards for innovative behavior; infrastructure to communicate ideas, knowledge and problems; consideration of employee interest; room for creativity; flexibility of work; and correct handling of mistakes.

An exploratory multiple case study approach undertaken by Dombrowski et al. (2007) resulted in the identification of the different salient elements of innovation culture. These are innovative mission and vision statements, democratic communication, safe spaces, flexibility, collaboration, boundary spanning, and incentives. The organizational dimension is the unit of analysis of most studies on innovation culture (Eynde et al., 2015), which generally used the components of organizational culture in finding the most effective parameters for innovation (Sadegh Sharifirad \& Ataei, 2012). A few validated scales such as the Competing Values Framework (CVF) and the Radiography of Innovation CultureMultidimensional Questionnaire (RIC-MQ) have been influential and extensively used models in organizational culture research. In terms of theoretical stance, different organizational studies were commonly anchored to capability and resource theories, theory of the firm, and control theory (Claver et al., 1998; Alm \& Jonsson, 2014; and Büschgens et al., 2013), which placed the limited applicability of innovation culture mostly in the context of private and manufacturing organizations.

This study argues that an organization's productivity in general is influenced by factors such as organization's capacity, external operating environment, the internal environment, resources, and management. In fact, previous studies linked innovation culture with innovation outcomes and performance outcomes (Jin et al., 2018; and Dobni, 2008). The latter emphasized that firms with a strong culture will have a positive and significant impact on performance outcomes. In this model, a culture supporting innovation engages behaviors that would value creativity, risk-taking, freedom, teamwork, be value-seeking 
and solutions-oriented, communicative, instill trust and respect, and be quick on the uptake in making decisions. Furthermore, innovation outcomes are influenced by a number of factors such as the individual technical skills and competencies and the organizational culture conducive for innovations (Smith et al., 2011; Prajogo \& Ahmed, 2006). Understood as a dimension of organizational culture, a way of thinking, innovative attitude, behavior and value system, a technological vision, tradition, and as a process shared by those who are involved in the innovation process (Claver et al., 1998; Anderson et al., 2012; and Alm \& Jonsson, 2014), we concur with the ideas of Eynde et al. (2015) and Jucevicius (2010) that the term "innovation culture" is multidimensional.

Meanwhile, in a knowledge-based economy, R\&D outputs such as scholarly articles and publications, knowledge, technologies, products, and inventions are important contributory factors (Roxas-Soriano et al., 2020). The academe, primarily HEls, are the main producers of R\&D outputs such as scientific publications, patents, as well as business enterprises and employment (Regadio \& Tullao, 2015). However, R\&D activities particularly in public HEls may cause tensions with instruction (e.g. teaching engagements) and extension (e.g. outreach commitments) capacities of the organization, which is also compounded by limited and differences in resource allocation and policies (Roxas-Soriano et al., 2020).

This study was framed within the perspective of R\&D productivity among public HEls with the belief that innovation depends largely on the quality of local universities, the internationalization of local inventions, and the quality of scientific publications (Cornell University, INSEAD, \& WIPO, 2019). This study also heeds the need to optimize productivity of public HEls in terms of production of scientific knowledge and technology, which can ultimately help attain economic development (NEDA, 2017) as well as in response to the demands of the 21st century. We also recognized the need for a better understanding of the concept of innovation culture, including its dimensions and elements, as experienced in the academe. Furthermore, we placed innovation culture not only in the context of academic organizations but also as a social-ordering approach to harnessing human (innovative traits and behaviors) and non-human organizational factors (organizational policies, structure, resources, and processes) toward improved productivity of public HEls despite numerous challenges and setbacks in doing R\&D in the organization.

The present paper explored how public HEls, as a unique type of organization, can hasten organizational productivity despite the environmental and institutional challenges besetting their R\&D activities. This particular setup leads us to pose the following research questions:

- What are the dimensions of innovation culture in the context of public HEls?

- How can this be utilized to improve the organizational R\&D productivity of public HE/s?

This study first analyzed and presented the institutional statements (e.g. mission and vision statement) of the four public HEls as well as the narratives of the participants pertaining to their R\&D tasks and activities in the university. Likewise, it reviewed and synthesized existing innovation culture frameworks, dimensions, and elements as well as presented 
some assessment tools used in previous studies, which further helped in situating the current, albeit, limited application of the concept of innovation culture in organizations. The second part introduced the analyses of the meanings and roles of innovation culture in relation to R\&D productivity in terms of producing inventions, utility models, and scientific publications and other forms of intellectual property (IP). Likewise, the managerial/leader as well as institutional concerns in doing R\&D were also discussed and explained through to the attributes and building blocks as well as to the dimensions and elements of innovation culture that were experienced and provided by the participants.

\section{Understanding the Role of InNovation Culture in Organizational Performance}

An organization's performance, in general, is influenced by factors such as the organization's capacity to innovate, the external operating environment, the internal environment, resources, and management. Innovation capacity determines how effectively an enterprise can undertake the innovation process (Smith et al., 2011). Its broad features include a combination of: (1) scientific, entrepreneurial, managerial, and other skills and knowledge; (2) partnerships, alliances, and network; (3) routines, organizational culture, and traditional practices that pattern the propensity to innovate; (4) an ability for continuously learning how to use knowledge more effectively; and (5) clusters of supportive policies and other incentives, governance structures, and the nature of the policy process (Rajalahti et al., 2008).

Capacity-building leads directly to stronger innovation performance (Smith et al., 2011). This relates to the conceptual framework of Choi \& Lim (2017), which highlighted the internal and external factors of innovation moderating the relationship between innovation capacity and performance. Moreover, the innovation capacity model also highlights the role of culture as an important factor of innovation. Hilmarsson et al. (2014), in their innovation performance model, relate that innovation performance is an overall result of the influence of innovation culture and market orientation in the front-end and back-end aspects of the generation and conversion of ideas into products of innovation.

The Global Innovation Index highlights the importance of investments in R\&D to scale up grassroots innovations and local communities so that technology development addresses the needs and aspirations, particularly of low- and middle-income economies (Cornell University, INSEAD, \& WIPO, 2018). As a driver of innovation, R\&D must consist of programs that focus on knowledge creation or its application to the creation of systems, methods, materials, or technologies.

In the context of manufacturing and private firms, a strong organizational innovation culture will motivate employees to participate in decision-making (Shahzad et al., 2017) and can stimulate innovative behavior and foster a sense of commitment to innovate among the members of an organization (Naranjo-Valencia et al., 2010). Certain cultural norms, such as trust and openness, awards and rewards, and autonomy and flexibility, facilitate an innovative climate in organizations (Efrat, 2014). This paper not only unpacks the concept of innovation culture in public organizations, particularly HEls. This study presents 
innovation culture as viewed by R\&D administrators and managers, innovators, and research personnel in relation to $R \& D$ performance.

In framing innovation culture as a multi-dimensional concept, this study looked at the intention, infrastructure, and the behavior necessary to influence R\&D productivity in public organizations such HEls. Guided by Institutional Theory (Meyer and Rowan, 1977), this study argues that everything that happens in organizations is not only brought about by rational actions but also by 'irrationalities' arising within the institutional context that surrounds organizational actors. This study considered the Actor-Network Theory (ANT) by Callon, Latour, \& Law (1980) as cited by Michael (2017). The ANT focuses on the processes and approaches to social ordering, which considers the roles of human and non-human (e.g. technologies) entities in the microsocial processes. Moreover, the ANT considered intermediaries such as physical and environmental factors (e.g. technologies) that prescribe and proscribe the activities of the actors and eventually bind them to particular networks.

METHODOLOGY

A qualitative case study research approach was used to allow for more flexible methods to answer the main research questions while exploring innovation culture in the context of academic organization, particularly public HEls. Such an approach aids in exploring innovation culture as viewed and experienced by the participants of this study. Consequently, this paper relied on primary qualitative data from the in-depth interviews and series of focus group discussions (FGDs) conducted from February to March 2019 in four selected public HEls representing state universities and colleges that are doing R\&D in the fields of agriculture and natural resources only. Furthermore, these organizations were purposively selected from provinces of the Philippines to situate the role of innovation culture in relation to individual productivity in terms of producing patents and inventions, utility models and other intellectual property (IP), and scientific publications (e.g. published journal articles, books, and manuals) from their R\&D activities in the university.

A synthesis of literature was undertaken to initially establish the different dimensions of innovation culture. It began with scanning and review of carefully selected studies, which led to the identification of key dimensions of innovation culture. Various descriptions, research instrument contents, and interview and research guide questions from previous studies were extracted, coded, categorized, and synthesized. Through this process, the dimensions of innovation culture were synthesized, which led to the formulation of interview and FGD guide questions. These questions allowed the participants to share their experiences in planning, implementing, and monitoring R\&D projects in the university, including the challenges faced as well as the culture that they observed and experienced in the organization. Furthermore, the guide questions for the in-depth key informant interviews were reviewed by experts who are specialists in the fields of technology and innovation management, R\&D administration and management, formal organizations, and instructional materials development.

This study had 32 FGD participants composed of faculty-research project personnel. Likewise, the in-depth interviews involved 8 participants composed of innovators and R\&D 
managers and administrators in the HEls. In general, the participants were selected based on the following qualities: (1) those who have been in the organization and are involved in the R\&D activities for at least five years; (2) those who represent public HEls that successfully undertake instruction, research and extension as manifested by teaching effectiveness, research competence, active community service, and efficient management of resources.

Data from the in-depth interviews and FGDs were transcribed and analyzed using explicitation techniques to build up themes regarding innovation and innovation culture. The transcribed data were read and re-read to extract significant statements and meaning units that provide participants' descriptions and insights on the specific elements and subdimensions of innovation culture as well as their experiences in the R\&D programs and activities in the organization. The significant statements were further analyzed clustering together to identify categories. Initial categories were subjected to thematic analysis by examining similarities and relationships among them. Content and thematic analyses of the institutional statements and narratives of the participants of the study led to the understanding of the organizational culture as well as nature of research endeavors of each organization. Likewise, institutional statements of the public HEls such as philosophy, vision, mission, organizational goal statements as well as list of research projects were analyzed in this study. Furthermore, qualitative analysis was facilitated using QDA Miner Lite, a computer-assisted qualitative analysis software.

RESULTS AND DISCUSSION

\section{UNPACKING THE DIMENSIONS OF INNOVATION CULTURE IN ORGANIZATIONS}

A systematic literature review unpacked and synthesized the different dimensions and elements of innovation culture from previous studies, which are mostly from management and business organization perspectives. Analysis of extracted meaning units was done to sort out similar and overlapping elements of innovation culture. Three main dimensions of innovation culture were identified. These are (1) organizational, (2) human and behavioral, and (3) network and partnership (Table 1). The organizational dimension is composed of organizational climate, design, values, communication systems, conflict management, processes, and rewards and incentives that promote an innovation-conducive organizational culture. The human and behavioral dimensions on the other hand presents the innovative traits of individuals, teams, groups, and leaders that make up an organization. Lastly, the network and partnership dimension of innovation culture typifies the collaboration and market and customer orientation activities of an innovative organization. The elements and characteristics were clustered according to each subdimension. Table 1 provides a synthesis of the dimensions, elements, and/or characteristics of innovation culture from various authors and/or researchers.

Other authors pointed out the need to identify how innovation culture values and practices influence the economic performance of an organization and how it affects the performance of organizations in other cultural contexts (Anderson et al., 2012; and Alm \& Jonsson, 2014). From the models and frameworks of innovation culture presented above, it 
can be observed that the concept applies well in the context of private and manufacturing organizations and suggests the need for further investigation in different organizational contexts. This includes the validation analysis of the elements of innovation culture that were measured and characterizing the implications to innovation processes and outputs of the organizations. A common recommendation of these authors focuses on the need for context-based approaches to understand other dimensions of innovation culture in different organizations. However, the study attempted to apply these dimensions of innovation culture in the context of public HEls, especially in relation to the conduct of research and the improvement in $R \& D$ performance of the organization. The study first probed the institutional statements of each public $\mathrm{HEl}$ as well as the narratives of the participants of the study to further understand what innovation is in academic organizations.

\section{ASPECTS OF INNOVATION IN ACADEMIC ORGANIZATIONS}

Higher education institutions play an important role in maintaining the dynamic between research and extension continuum to ensure that $R \& D$ results will be able to help in national development through effective technology transfer. As such, faculty members of any $\mathrm{HEl}$ are expected to strike a balance between doing research and instruction as well as other mandates of the HEI. Mainly, these expectations are embedded in the institutional statements of HEls.

Institutional statements such as the vision, mission, and philosophy form the foundation of objectives and strategies of an organization, which determine a culture that is favorable to its cause (Rajasekar, 2013). On the other hand, a cultural perspective on institutional statements encompasses the philosophy, identity, and values, which give the meaning to the goals, norms, decisions, actions, and everyday behavior of members of the organization (Babnik et al., 2014).

We characterized the organizational culture specific for doing R\&D in the HEls by analyzing their institutional statements (e.g. vision, mission, and philosophy). Likewise, the narratives of the research participants' views of R\&D innovation were also analyzed. Furthermore, the interpretation of the themes reflected the six aspects of innovation proposed by Ahmed and Shepherd (2010) as cited by Szłapka et al., (2017).

\section{INNOVATION AS CREATION}

According to Ahmed and Shepherd (2010), the first aspect of innovation is "creation", which highlights the use of resources such as people, time and money to invent or develop a new product, service, way of doing things, or way of thinking about things. Examples lifted from institutional statements of the four HEls were 'market-driven innovations', 'development and promotion of technologies', 'quality and excellent services', 'scientific and innovative technology', which were interpreted as innovation as (a) a product or service and (b) technological advancement (Table 2). 
Likewise, the views of the participants regarding the creation aspect of innovation revealed similar themes when asked about the concept of innovation and its role in doing research in the university. The following are some of the responses of the participants:

"Innovation is about technology development, value-adding are things that come to our minds about innovation." (FGD note, HE/1)

"There's commercial value, an invention with a market or creation with income. Something that will improve [the life of] an individual." (Key informant 1, HEI3)

"Unique, patentable application, new technology, modern, new concept, improved version, discovery, R\&D program, something new, new methods. " (Key informant 1, HEI2)

\section{INNOVATION AS AN EVENT}

The "event" aspect of innovation focuses on occurrences such as acquiring, supporting, using, or adopting a product, service, or idea (Ahmed and Shepherd, 2010). An example of this aspect of innovation includes 'partnership with key sectors of development' and 'expand their intellectual horizons', which pertain to occurrences of collaboration and widening of knowledge and competencies (Table 3).

Similarly, some participants also reflected the themes developed under this aspect of innovation. Here are some of their responses:

"You need to make friends and collaborate. We include/involve others in the research proposal especially when they have the needed resources and equipment." (Key informant 1, HEI3)

"...we continue to build expertise and being up-to-date, we build more people in the fields of nanotechnology, smart agriculture, data analytics. We collaborate with other universities for expertise." (Key informant 1, HE/1)

"Linkaging is highly important because we believe no man is an island. We have our strength, we have our weakness and if we have the network then that could help us, that could compliment with the strength that we have." (Key informant 2, HE/1)

\section{INNOVATION AS DIFFUSION AND LEARNING}

The "diffusion and learning" aspect of innovation pertains to discrete and distinct events, such as the development of a single product, service, idea, or decision for a specific purpose or agenda (Ahmed and Shepherd, 2010). Examples of this aspect that were obtained from the institutional statements include 'appropriate approaches for sustainable agro-industrial development' and 'quality education and professional training' (Table 4). 
This aspect of innovation was also manifested in the following responses of the participants, specifically on the purpose of quality education and professional learning among the students and faculty members of the university:

"We continue to allow them to go on study leave for their graduate program. Mostly PhDs." (Key informant 1, HE/1)

"We have a lot of catching up to do in that area and the thing that we did first was to raise again the awareness, and then capability building, although we already have an incentive and reward system in place." (Key informant 1, HEI4)

\section{INNOVATION AS RADICAL OR INCREMENTAL CHANGE}

The "radical or incremental change" aspect of innovation describes innovations as minor adjustments or discontinuous in nature (Ahmed and Shepherd, 2010). This aspect also highlights that radical or incremental change are deemed necessary in realizing a goal or serving a cause. Phrases lifted from the institutional statements that relate to this aspect were categorized as 'a shift to having output-based and realistic policies, goals, and strategies', 'a shift to human resources development', 'a shift to promoting positive values in the professional and advanced technological fields' (Table 5).

Under this aspect of innovation, the participants agreed that innovation needs a shift to not only developing technologies and services but also to producing quality graduates (human resources) as well as continuous improvement in research-related policies in the university. The following are some of their responses:

"Improvements of products, processes. The product that we mean here are not only the products based on materials, but we are referring also to the kind of 'products' that they are after graduation." (FGD note, HEI4)

"It's only a simple technology of changing hatchery management to increase production. We thought it simple yet made a huge impact in the industry." (Key informant 2, HE/1)

"There were some amendments made in the research manual. Every time we encounter problems, we make sure changes and/or clarifications are reflected in the policies." (Key informant 1, HEI2)

\section{INNOVATION AS A PROCESS}

The "process" aspect of innovation highlights firm-level series of activities that are carried out to produce an outcome (Ahmed and Shepherd, 2010). It also highlights the organization-specific approach to innovation. Phrases from the institutional statements depicted this aspect of innovation, which were further categorized into (a) an integrated process of human resources, knowledge, and technology development and (b) innovation as a path toward sustainable development (Table 6). 
In addition, the following insights shared by the participants were deemed aligned with the view that innovation is an integrated process of developing human and other resources of the organization:

\section{"We try to capitalize on our strengths and likewise improve on the weaknesses. " (FGD note, HEI3) \\ "Better innovation, better policy observation, better products to do. Innovativeness is validated through the graduates, quality of research papers, and number of inventions. "(FGD note, HEI4)}

\section{INNOVATION AS A CONTEXT}

The "context" aspect focuses on institutional frameworks and socio-political networks as important factors in the act of innovation, which are beyond the confines of an organization (Ahmed and Shepherd, 2010). Some key phrases present innovation as a goal for achieving excellence and relevance, and at the same time, an imperative in a changing and dynamic context. These phrases include institutional statements such as 'address everchanging educational needs and services' and 'globally competitive, work-ready, sociallyresponsible' (Table 7$)$.

Meanwhile, participants shared that innovation in the organization is an imperative, which means that innovation is essential in a diverse R\&D culture and direction, as well as in a continuously growing intellectual R\&D horizons and expertise.

"One must have a clear picture of the culture for R\&D and its direction. Diversity in the organization is needed. "(FGD note, HEI2)

\section{"Good mentoring entails openness to new things such as advanced frontier science like nanotechnology, biotechnology, data science and then of course in SMART farming. A mentor must have a wide intellectual horizon to be an effective one." (Key informant 1, HE/1)}

Based on the institutional statements of the four public HEIs, innovation in their organization provides a holistic framework for research and instruction as well as continuous development. In a nutshell, the institutional statements portray innovation as "a shift to output-based and realistic policies" and "human resource development" (Change), "a product or service for a specific group of people or sector" (Diffusion and Learning), "a process of technology and information generation, human resource development, communication, and partnership" (Process) and as "development of a product or service" (Creation). As such, innovation can be thought of as an output, product, or service (e.g. creation), a process (e.g. diffusion, change, or event), and a system made of up institutions and actors affected both by internal and external factors (e.g. context). Innovation as a product or output, service, process, and a system are the common views and concepts presented in extant literature, especially in those referenced for this study. This study agrees with Szłapka et al. (2017) in saying that understanding the aspects of innovation in an organization is an imperative since the concept itself is wide. 
Furthermore, the narratives of the participants confirmed that innovation is embedded already in the organization. In the following statements, innovation is important in public HEls as it serves three purposes: (1) as a core function of the university and of the faculty members that can help them carry out their research, extension, and instruction tasks, (2) a priority for its importance in keeping the organization on track, and (3) an agenda/goal of the organization:

"...it is one of the four core functions, we needed to come up with research and all but it all boils down at the end of the day for every researcher." (FGD note, HEI4)

"Yes. [It is] in our vision, to be a globally-competitive university, in which technology innovation is being given priority." (Key informant 1, HE/3)

"Innovation is important in keeping our R\&D activities grounded (on the vision mission) of the university..." (FGD note, HEIT)

"Innovation in research, which is the R\&D agenda, we first align it with the thrust of the organization. We revise and update it according to the changes in the agenda of government line agencies. " (Key informant 1,

HEI2)

As such, we can now say that institutional statements such as the vision and mission statements of the university can help explain how innovation in the context of doing R\&D in the university is being valued and pushed in the organization. Moreover, the aspects of innovations that were manifested from the institutional statements of the four HEls can help us describe the organizational culture for innovation as well as the work behavior espoused by the participants regarding R\&D in the university.

\section{InNovation Culture in Public HEIs: Attributes ANd BuILDing BlOCKS}

The study also elicited two meaningful themes regarding participants' cognition of innovation culture in their organization, particularly in R\&D (Table 8). The first theme, attributes of innovation culture, includes the concepts of collectivity, relevance and competitiveness, and sustainability. According to the participants, innovation culture helps promote collectivization and brings people together by promoting a sense of community and a common sense of purpose aligned with the thrust of organization. Innovation culture not only helps the organization develop new products and technologies but is also instrumental in sustaining its success, achievements and accomplishments by promoting competitiveness and relevance in terms of producing new and better-quality products and services, and promotes competitiveness, productivity, and performance among the individuals in the organization. Under the theme building blocks of innovation culture in the organization, there remained the components of innovation - the people, products, and the processes. This theme can also help explain the perceived strength of innovation culture in their organization. According to the participants of the study, an organization with a culture for innovation can be observed through its people, products, and process. 
Likewise, innovation culture should also be institutionalized in the organization, which means it should be explicitly stated in the mandates as well as in the vision and mission statements of the organization. Lastly, innovation culture is also manifested by a "nurturing and listening" climate in the organization.

This study extends our understanding of the concept of innovation culture in organizations, both public and private. In addition to the elements of innovation culture synthesized and presented in this paper earlier, this study described seemingly important attributes of innovation culture such as having a sense of community and purpose and valuing competitiveness and relevance. These attributes further described the 'organizational innovation atmosphere', which was espoused by Dobni (2008) as one of the multi-dimensional organizational innovation cultures. Likewise, the people, products, outcomes, policies and processes as building blocks for innovation put in context the organizational and human and behavioral dimensions of innovation culture in public organizations with great emphasis on explicit institutional innovation statements and plans that can influence performance and productivity among members of the organization. Lastly, this study highlights that, as an aspect of organizational culture, innovation culture also has many layers such as values, norms, beliefs, and basic assumptions that shape the organization's intention for innovation.

\section{Role of InNOVATION CULtURE In Public HEIS: TOWARd IMPROVEd PRODUCTIVITY}

The study earlier highlights the layers of organizational culture such as values, norms, beliefs, and basic assumptions which shape the organization's intention for innovation. Furthermore, applying innovation culture in the context of academic organizations, this study also highlights that the dimensions of innovation culture must be shared among members of the organization to overcome the challenges in doing research.

The analyses of the issues and problems concerning the conduct of R\&D in the university surfaced two important themes where policy interventions can emanate (Table 9). The first theme focuses on the managerial and/or leader concerns, which when addressed can help respond to the present issues and concerns in the conduct of research in the organization. Under this theme, issues and concerns include:

- delays in the implementation of research projects due to the tedious process of public procurement (e.g. bidding process),

- traditional mindset of the faculty regarding their core tasks and functions in the university that limits their drive and motivation to engage more in doing research,

- poor appreciation of the research-extension continuum, which limits the generation of innovative and collaborative ideas and projects that promote synergy and complementation of expertise and resources for both areas,

- lack of essential skills/capacities to plan, develop, and implement research initiatives that further limit faculty motivation to get involved in research activities in the university, and 
- issues pertaining to appraisal of performances in the area research which participants believed to be one of the reasons that limit motivation and drive of the faculty.

The second theme pertains to institutional environment concerns, which limit actions and motivations of the faculty in conducting research. Issues and concerns under this theme include the lack of resources (e.g. innovation units/experts, infrastructure) devoted to research and innovation activities of the organization, the lack of clear policies as well as indicators for research and innovation activities and accomplishments of faculty members, and the lack of flexibility and creativity to mitigate the implications of tedious processes involved in public procurement. Likewise, the complexity of the issues and concerns shared by the participants were overlapping, for instance issues regarding the procurement process and lack of resources called for managerial/leader and institutional environment concerns.

A collective description of each theme is presented in Table 10. In general, both themes greatly affect the drive and motivation of the university faculty members in engaging and doing research in addition to workloads in teaching and instruction. The theme of managerial/leader concerns described the need to change the mindset of the individual faculty members to embrace research functions of the university as well as the necessary faculty encouragements and motivation by managers and leaders through mentoring and coaching to lessen and mitigate individual and institutional burdens affecting research initiatives and activities in the organization and to foster generation of innovative ideas and interactions among units and individuals in the organization. The institutional concerns theme pertains to the need to address, as an organization, the issues on workload, relevant performance assessment for R\&D, weak research culture or mindset among the individuals, limited resources for research and innovation, and mainstreaming training and capability building for research. These findings relate to the insights of Perkmann et al. (2013), primarily on the analytical framework of external engagement by academic researchers. Their work cited individual, organizational, and institutional factors that are affecting the engagements of academic researchers. These factors can greatly influence the scientific, educational, and commercial outputs of the academic researchers.

According to Stempfle (2011), performance measurement is often detrimental to organizations, thus needs to be constantly adjusted by engaging employees to share their own ideas. Doing so empowers the employee to think they are contributing to the organization. For Soken \& Barnes (2014), what gets measured is typically what gets done. Thus, performance management should include balanced appraisal of outputs and activities concerning the research, instruction, extension, and production functions of the university and of the faculty. Moreover, Chiesa et al. (2009) suggested that performance measurement in R\&D is used to exert control over activities and support critical management decisions, thus spelling the efficiency and effectiveness of the organization. It is also used as a means to improve the motivation of researchers. For instance, policies and guidelines such as the strategic performance management system, performance-based 
bonus, and national budget circular for promotion of faculty encourage them to engage in research to gain higher points.

On the other hand, Torrentira (2018) suggested that in promoting research culture among faculty members, consideration must be given to motivation and incentive and to developing the institution's endowment of research skills through recruitment and/or education and training. Another concern was on strengthening the complementation of research and extension, hence the need to rethink performance management systems capturing not only the corresponding performance indicators and balanced workloads but also promoting innovativeness of the individuals and teams involved in R\&D in the university.

With reference to social ordering (e.g. toward improving R\&D productivity) espoused by the Actor-Network Theory, non-human factors such as institutional statements must help advocate, prescribe, and shape the innovative behavior and the culture for innovation in the public HEls. Hence, it is vital to make these dimensions more explicit in the institutional policies such as the mission, vision, goal and philosophy statement of each organization.

The participants also expressed that skills and competencies are essential in performing their research, extension, and instruction tasks, which relate to the role of continuous improvement and learning organization aspects of innovation culture. The participants also considered these as motivation to engage in R\&D. To this, Torrentira (2018) emphasized that continuous training, technical assistance, provision of guidance, support, and direction are some of the key components of sustainable research collaborations between the university and the industry and government agencies. Meanwhile, Gamusa \& Pacolor, (2019) suggested that attitude alone is not sufficient; a balanced mix of attitude towards work and competence is key to quality output. They further proposed continuous capability building on key areas (specialized doctoral, masters and short-term training/industry experience/immersion) and more international exposure of the faculty are to be executed strategically. These are aligned with the recommendation made by Quimbo \& Sulabo (2014) that universities must have a viable and strong faculty and staff development program, specifically, capability of the faculty should be enhanced to prepare proposals and conduct researches through provision of appropriate training programs.

In addition to issues on workload and tedious procurement processes, another common challenge faced by R\&D personnel include the need to strengthen and/or reinforce the resources that are essential in innovation management activities such as R\&D proposal packaging, IP protection, and technology transfer and commercialization. According to them, such difficulties necessitate not only creativity and flexibility in task management but also orientation to technological innovation and more explicit innovation processes. This highlights the importance of flexibility and creativity. Creativity requires a conducive environment (Roffeei et al., 2016 and 2018; Blom \& Hertzberg, 2018) and institutions that are flexible to adapt to changes and re-adjust relevant rules, regulations, norms, and beliefs. Moreover, for Martins \& Terblanche (2003), creativity in an organization can only be determined if the vision and mission statements mention creativity and innovation. 
Lessons and insights of participants regarding the challenges and difficulties they experienced in the organization were drawn from this study. First is promoting creativity in the performance management system for research and extension. Performance management should include balanced appraisal of outputs and activities concerning the research, instruction, extension, and production functions of the university and of the faculty. Performance measurement in R\&D is used to exert control over activities and support critical management decisions, thus spelling the efficiency and effectiveness of the organization. It is also used as a means to improve the motivation of researchers (Chiesa et al. 2009). For instance, policies and guidelines such as the strategic performance management system, performance-based bonus, and national budget circular for promotion of faculty encourage them to engage in research to gain higher points.

Second is providing more flexible resources for $R \& D$ and innovation activities to lessen the impacts of procurement delays. Reducing resistance to changes in the organization and in building research culture in the organization entails availability of ample resources for R\&D activities (Quimbo \& Sulabo, 2014; and Gamusa \& Pacolor, 2019). In addition, increasing and/or realigning funds for research can help minimize the impeding factors to research productivity in the organization.

Third, the need for a responsive training and capability development for research and innovation. Universities must have a viable and strong faculty and staff development program on preparing and packaging R\&D proposals and conducting research.

Fourth is promoting flexibility in task management. Common challenges faced by R\&D personnel include delays in the implementation of projects due to tedious procurement processes, lack of important resources, and heavy workload. While these issues are significantly policy- and guideline-related, they are also deemed to be a managerial/leader concern. Thus, with these limitations, flexibility is essential. Flexibility means to continually adapt to change and to readily commit and redirect resources for innovative opportunities while creativity means being resourceful in the methods of operations and sharing of new ideas in the organization. Flexibility of work and informality support the dynamic exchanges of knowledge and ideas within and outside the organizations (Petraite \& Ceicyte, 2012).

Lastly, staff coaching and mentoring by leaders and managers. Coaching and mentoring can inspire and empower employees, promote commitment, increase productivity, grow talent, and encourage success (Serrat, 2010). As a dimension of transformational leadership, coaching and encouragement from leaders is necessary to get the group working (Jong \& van Lind Wijngaarden, 1999). Coaching also benefits the leaders and managers as it provides them opportunity to reflect on their own values, beliefs and behavioral patterns (Stempfle, 2011). Mentoring helps build an inclusive work environment since it fosters good relationships beyond the ranks and hierarchies, promotes trust, and encourages mutual learning (Pless \& Maak, 2004). Faculty members are not doing research due to a lack of confidence in their research skills. Mentoring backed up by appropriate policies are essential for faculty involvement and at the same time encourage active involvement in R\&D activities. 
CONCLUSION

This study extends our understanding of innovation and innovation culture in the context of both private and public organizations, primarily its relevance and potentials in influencing and promoting R\&D productivity among faculty-researchers in public HEls. We can say that innovation and innovation culture are both implicitly and explicitly embedded in the institutional statements of each organization as well as in the values that the participants attach to it. Hence, it is important to make the intention for innovation more explicit as this can determine how the individuals should promote and value it in the organization.

We further understood the concept of innovation culture by synthesizing the different human and non-human dimensions of innovation culture and further learned its multidimensionality. These dimensions reflect that layers of organizational culture such as values, norms, beliefs, and basic assumptions, which shape the innovativeness of the organization. From this study, we learned the importance of innovation culture in promoting individual productivity amidst the challenges that make R\&D in public HEls even more of a daunting task. The managerial and institutional concerns can greatly affect the drive and motivation to engage and conduct research in addition to teaching and instruction tasks in the university. Specifically, we learned that having creativity and flexibility, innovation resources, training and capacity development, and coaching and mentoring were the key elements or building blocks manifested in the narratives of the participants primarily in addressing the managerial and institutional challenges in the organization. Extending the concept of innovation culture in the academe, particularly in terms of doing R\&D, we learned that innovation culture has potential for overcoming various organizational and institutional challenges and concerns.

The study also contributed in terms of adding innovation culture as a layer in current analytical frameworks that can help explain the quality of engagements and balancing productivity in terms of instruction/academic, scientific (e.g. R\&D outputs such as journal publications), and commercial/extension outputs (e.g. technologies, inventions) of facultyresearchers in the university.

This study is limited in terms of using specific models to determine the level of R\&D productivity in the selected organizations. Hence, research areas to consider may include relating the different dimensions and elements of innovation culture in academic institutions as a social-ordering approach toward improved R\&D productivity. It is also noteworthy to consider exploring how leaders and managers help in forming innovation culture in public HEls. Likewise, it is imperative to know how such culture influences academic organizations, both local and international academic contexts, in producing quality and innovative graduates.

REFERENCES

Abdul Halim, H., Ahmad, N. H., Ramayah, T., Hanifah, H., Taghizadeh, S. K., \& Mohamad, M. N. (2015). Towards an Innovation Culture: Enhancing Innovative Performance of Malaysian SMEs. 
Academic Journal of Interdisciplinary Studies, 4(2), 85-94. Retrieved August 1, 2019 from http://www.richtmann.org/journal/index.php/ajis/article/view/7144

Aksoy, H. (2017). How Do Innovation Culture, Marketing Innovation and Product Innovation Affect the Market Performance of Small and Medium-sized Enterprises (SMEs)? Technology in Society, 51, 133-141.

Ahmed P.K., \& Shepherd C. (2010). Innovation Management: Context, Strategies, Systems and Processes (1st ed). Harlow: Financial Times Prentice Hall.

Alm, C. J., \& Jönsson, E. (2014). Innovation Culture in Five Dimensions: Identifying Cultural Success Factors and Barriers for Innovation [Unpublished master's thesis]. Division of Innovation Engineering and Management, Chalmers University of Technology. Retrieved September 5, 2019 from http://publications.lib.chalmers.se/records/fulltext/199661/199661.pdf

Anderson, A., El Harbi, S., \& Amamou, M. (2012). Innovation Culture and the Economic Performance of Tunisian ICT firms. Int. J. Entrepreneurship and Innovation Management, 16(3), 191-208.

Babnik, K., Breznik, K., Dermol, V., \& Trunk Širca, N. (2014). The Mission Statement: Organisational Culture Perspective. Industrial Management \& Data Systems, 114(4), 612-627. https://doi.org/10.1108/IMDS-10-2013-0455

Blom, L., \& Hertzberg, E. (2018). Creative Climate: A Prerequisite for Supporting an Innovation Culture [Unpublished master's thesis). University of Gothenburg. Retrieved December 3, 2019 from https://gupea.ub.gu.se/bitstream/2077/57229/1/gupea 207757229 1.pdf

Brettel, M., \& Cleven, N. J. (2011). Innovation Culture, Collaboration with External Partners and NPD Performance. Creativity and Innovation Management, 20(4), 253-272. https://doi.org/10.1111/j.1467-8691.2011.00617.x

Büschgens, T., Bausch, A., \& Balkin, D. B. (2013). Organizational Culture and Innovation: A MetaAnalytic Review. Journal of Product Innovation Management, 30(4), 763-781. https://doi.org/10.1111/jpim.12021

Chiesa, V., Frattini, F., Lazzarotti, V., \& Manzini, R. (2009). Performance Measurement in R\&D: Exploring the Interplay Between Measurement Objectives, Dimensions of Performance and Contextual Factors. R\&D Management, 39(5), 487-519. https://doi.org/10.1111/j.14679310.2009.00554.x

Choi, Y., \& Lim, U. (2017). Contextual Factors Affecting the Innovation Performance of Manufacturing SMEs in Korea: A structural equation modeling approach. Sustainability, 9(7), 1193. https://doi.org/10.3390/su9071193

Claver, E., Llopis, J., Garcia, D., \& Hipolito, M. (1998). Organizational Culture for Innovation and New Technological Behavior. Journal of High Technology Management Research, 9(1), 55-68.

Cornell University, INSEAD, \& WIPO (2019); The Global Innovation Index 2019: Creating Healthy Lives-The Future of Medical Innovation, Ithaca, Fontainebleau, and Geneva. Retrieved September 21, 2019 from https://www.wipo.int/edocs/pubdocs/en/wipo pub_gii 2019.pdf

Cornell University, INSEAD, \& WIPO. (2018). Global Innovation Index 2018: Energizing the World with Innovation. Ithaca, Fontainebleau, and Geneva. Retrieved January 5, 2019 from https://wipo.int/edocs/pubdocs/en/wipo_pub_gii_2018.pdf 
Davies, M., \& Buisine, S. (2018). Innovation Culture in Organizations. In M. Chouteau, J. Forest, \& C. Nguyen (Eds.), Science, Technology and Innovation Culture. ISTE Ltd and John Wiley \& Sons, Inc.

Dobni, B.C. (2008). Measuring Innovation Culture in Organizations: The Development of a Generalized Innovation Culture Construct Using Exploratory Factor Analysis. European Journal of Innovation Management, 11(4), 539-559. https://doi.org/10.1108/14601060810911156

Dombrowski, C., Kim, J. Y., Desouza, K. C., Braganza, A., Papagari, S., Baloh, P., \& Jha, S. (2007). Elements of Innovative Cultures. Knowledge and Process Management, 14(3), 190-202. https://doi.org/10.1002/kpm.279

Doroodian, M., Ab Rahman, M. N., Kamarulzaman, Y., \& Muhamad, N. (2014). Designing and Validating a Model for Measuring Innovation Capacity Construct. Advances in Decision Sciences, 2014(1), 11. https://doi.org/10.1155/2014/576596

Efrat, K. (2014). The Direct and Indirect Impact of Culture on Innovation. Technovation, 34(1), 12-20. https://doi.orgj.technovation.2013.08.003

Eynde, A., Cornejo-cañamares, M., Diaz-garcia, l., \& Muñoz, E. (2015). Measuring Innovation Culture: Development and Validation of a Multidimensional Questionnaire. Advances in Research, 4(2), 122-141. https://doi.org/10.9734/AIR/2015/15533

Gamusa, E. V., \& Pacolor, E. T. (2019). Research Productivity of SUC Managers in Eastern Visayas, Philippines, and their Leadership Orientation. Journal of Academic Research, 4(3), 23-30.

Hilmarsson, E., Oskarsson, G., \& Gudlaugsson, T. (2014). The Relationship Between Innovation Culture and Innovation Performance. International Journal of Business Research, 14(1), 86-95. https://doi.org/10.18374/ijbr-14-1.8

Jin, Z., Navare, J., \& Lynch, R. (2018). The Relationship Between Innovation Culture and Innovation Outcomes: Exploring the Effects of Sustainability Orientation and Firm Size. R\&D Management, 49(4), 607-623. https://doi.org/10.1111/radm.12351

Jong, J. J.P. De, \& Van Lind Wijngaarden, K. D. (1999). Individual Innovation: The Connection Between Leadership and Employees' Innovative Work. Ideas.Repec.Org. Retrieved December 1, 2019 from https://ideas.repec.org/p/eim/papers/r200604.html

Jucevicius, G. (2010). Culture vs. Cultures of Innovation: Conceptual Framework and Parameters for Assessment. In E. Tsui (Ed.), Proceedings of the 7th International Conference on Intellectual Capital, Knowledge Management \& Organizational Learning.

Lažnjak, J. (2011). Dimensions of National Innovation Culture in Croatia: Content Validity of Hofstede's Dimensions. Drustvena istrazivanja, 2 (4 (114), 1015-1038.

Linke, A., \& Ansgar, Z. (2011). Internal Communication and Innovation Culture: Developing A Change Framework. Journal of Communication Management, 15(4), 332-348.

Martins, E. C., \& Terblanche, F. (2003). Building Organisational Culture that Stimulates Creativity and Innovation. European Journal of Innovation Management, 6(1), 64-74.

Meyer, J., \& Rowan, B. (1977). Institutionalized Organizations: Formal Structure as Myth and Ceremony. American Journal of Sociology, 83(2), 340-363. Retrieved July 12, 2020, from www.jstor.org/stable/2778293 
Michael, M. (2017). Actor Network Theory. The Wiley-Blackwell Encyclopedia of Social Theory, 1, 1-4. https://doi.org/10.1002/9781118430873.est0002

Naranjo-Valencia, J. C., Sanz-Valle, R., \& Jiménez-Jiménez, D. (2010). Organizational Culture as Determinant of Product Innovation. European Journal of Innovation Management, 13(4), 466480. https://doi.org/10.1108/14601061011086294

NEDA. (2017). Philippine Development Plan 2017-2022. National Economic and Development Authority (NEDA): Ortigas Center, Pasig City 1605 Philippines. Retrieved June 19, 2020 from http://www.neda.gov.ph/wp-content/uploads/2017/12/Abridged-PDP-2017-2022_Final.pdf

Petraite, M., \& Ceicyte, J. (2012). The Features of Organizational Innovation Culture in Micro Enterprises: Case Studies from Lithuanian Creative Industries. Social Sciences, 762), 4-37. https://doi.org/10.5755/j01.ss.76.2.1953

Perkmann, M., Tartari, V., McKelvey, M., Autio, E., Broström, A., D’Este, P., Fini, R., Geuna, A., Grimaldi, R., Hughes, A., Krabel, S., Kitson, M., Llerena, P., Lissoni, F., Salter, A., Sobrero, M. (2013). Academic engagement and commercialisation: A review of the literature on universityindustry relations. Research Policy, 42(2), 423-442. https://doi.org/10.1016/j.respol.2012.09.007.

Pless, N., \& Maak, T. (2004). Building an Inclusive Diversity Culture: Principles, Processes and Practice. Journal of Business Ethics, 54(2), 129-147.

Prajogo, D.I., \& Ahmed, P.K. (2006). Relationships Between Innovation Stimulus, Innovation Capacity, and Innovation Performance. R\&D Management, 36(5), 499-515.

https://doi.org/10.1111/j.1467-9310.2006.00450.x

Quimbo, M.A.T., \& Sulabo, E.C. (2014). Research Productivity and Its Policy Implications in Higher Education Institutions. Studies in Higher Education, 39(10), 1955-1971.

https://doi.org/10.1080/03075079.2013.818639

Rajalahti, R., Janssen, W., \& Pehu, E. (2008). Agriculture and Rural Development Discussion Paper 38 Agricultural Innovation Systems: From Diagnostics toward Operational Practices.

https://www.agrilinks.org/sites/default/files/resource/files/ARDDiscussionPaper38.pdf

Rajasekar, J. (2013). A Comparative Analysis of Mission Statement Content and Readability. Journal of Management Policy and Practice, 14(6), 131-147. Retrieved June 20, 2019 from http://www.nabusinesspress.com/jmpp/rajasekarj_web14_6_.pdf

Rao, J., \& Weintraub, J. (2013). How Innovative Is Your Company's Culture? MIT Sloan Management Review, 54(3), 28-37. Retrieved August 27, 2019 from http://panopticinsight.com/wpcontent/uploads/2014/05/Rao-Weintraub-innov-culture.pdf

Regadio, C. J.Q., \& Tullao, T.S. (2015). The Role of the Government in Enhancing Research Productivity of SUCs and Private HEls in the Philippines. DLSU Research Congress 2015. http://dx.doi.org/10.13140/RG.2.1.2591.2161

Roffeei, S. H. M., Kamarulzaman, Y., \& Yusop, F. D. (2016). Innovation Culture in Higher Learning Institutions: A Proposed Framework. Procedia Social and Behavioral Sciences, 219(1), 401-408. https://doi.org/10.1016/j.sbspro.2016.05.064

Roffeei, S. H. M., Kamarulzaman, Y., \& Yusop, F. D. (2018). Determinants of Innovation Culture Amongst Higher Education Students. The Turkish Online Journal of Educational Technology, 171), 37-50. Retrieved June 1, 2020 from http://www.tojet.net/articles/v17i1/1715.pdf 
Roxas-Soriano, P., Morales, M. P. E., \& Reyes, W. S. (2020). Profiling the Research Culture of Philippine Higher Education Institutions. EDUCARE: International Journal for Educational Studies, 13(1), 1-16. https://doi.org/10.2121/edu-ijes.v13i1.1337.g1163

Sadegh Sharifirad, M., \& Ataei, V. (2012). Organizational Culture and Innovation Culture: Exploring the Relationships Between Constructs. Leadership \& Organization Development Journal, 33(5), 494-517. https://doi.org/10.1108/01437731211241274

Schertlin, P. (2018). Innovation Culture-Challenges and Opportunities [Unpublished bachelor's thesis]. Friedrich-Alexander-Universität Erlangen-Nürnberg. Retrieved June 1, 2020 from https://www.researchgate.net/publication/330882387_Innovation_Culture_Challenges and Opportunities

Serrat, O. (2010). Coaching and Mentoring. Washington, DC: Asian Development Bank. Retrieved December 3, 2019 from https://www.adb.org/publications/coaching-and-mentoring

Shahzad, F., Xiu, G., \& Shahbaz, M. (2017). Organizational Culture and Innovation Performance in Pakistan's Software Industry. Technology in Society, 51(1), 66-73.

https://doi.org/10.1016/j.techsoc.2017.08.002

Smith, A., Courvisanos, J., Tuck, J., \& Mceachern, S. (2011). Building Innovation Capacity: The Role of Human Capital Formation in Enterprises - A Review of the Literature. NCVER. Commonwealth of Australia. Retrieved September 21, 2019 from https://files.eric.ed.gov/fulltext/ED517803.pdf

Soken, N., \& Kim Barnes, B. (2014). What Kills Innovation? Your Role as A Leader in Supporting an Innovative Culture. Industrial and Commercial Training, 46(1), 7-15. https://doi.org/10.1108/ict09-2013-0057

Stempfle, J. (2011). Overcoming Organizational Fixation: Creating and Sustaining an Innovation Culture. The Journal of Creative Behavior, 45(2), 116-129. https://doi.org/10.1002/j.21626057.2011.tb01091.x

Stock, R. M., Six, B., \& Zacharias, N.A. (2013). Linking Multiple Layers of Innovation-oriented Corporate Culture, Product Program Innovativeness, and Business Performance: A Contingency Approach. Journal of the Academy of Marketing Science, 41(3), 283-299. https://doi.org/10.1007/s11747-012-0306-5

Szłapka, J. O., Stachowiak, A., Batz, A., \& Fertsch, P. M. (2017). The Level of Innovation in SMEs, the Determinants of Innovation and their Contribution to Development of Value Chains. Procedia Manufacturing, 11(1), 2203-2210. https://doi.org/10.1016/j.promfg.2017.07.367

Tian, M., Deng, P., Zhang, Y., \& Salmador, M. P. (2018). How Does Culture Influence Innovation? A Systematic Literature Review. Management Decision, 56(5), 1088-1107. https://doi.org/10.1108/md-05-2017-0462

Torrentira, M. C. (2018). Framework of Sustainable Research Collaborations in Philippine Universities: A case study. Review of Public Administration and Management, 06(03), 1-5. https://doi.org/10.4172/2315-7844.1000255

Xie, X., Wu, Y., \& Zeng, S. (2016). A Theory of Multi-dimensional Organizational Innovation Cultures and Innovation Performance in Transitional Economies: The Role of Team Cohesion. Chinese Management Studies, 10(3), 458-479. 
Zeqiri, J., \& Alija, S. (2016). The Organizational Culture Dimensions - The Case of an Independent Private University in Macedonia. Studia Universitatis Babe-Bolyai Oeconomica, 61(3), 20-31. https://doi.org/10.1515/subboec-2016-0002

BIOGRAPHIES

Dr. Paul Jersey G. Leron is a Senior Science Research Specialist at the Applied Communication Division of the Philippine Council for Agriculture, Aquatic and Natural Resources Research and Development of the Department of Science and Technology (DOST-PCAARRD) where he is tasked to plan and manage information, education, and communication (IEC) materials production and training programs and initiatives. He received his $\mathrm{PhD}$ in Development Studies at the University of the Philippines Los Baños (UPLB). His fields of interest include innovation and policy studies, strategic planning, knowledge management, and science communication. Dr. Leron can be contacted through his email p.leron@pcaarrd.dost.gov.ph or pgleron@up.edu.ph.

Dr. Rowena DT. Baconguis is a Professor at the Institute of Governance and Rural Development of the College of Public Affairs of the University of the Philippines Los Baños. She holds a doctorate degree in Extension Education. Her areas of specialization include extension policy analysis as well as training designing and management and participatory rural analysis and project development. Her research interests include technological innovation assessment studies, innovation systems analysis, knowledge management, volunteerism and development, rural development, and mainstreaming of climate change. Dr. Baconguis can be reached through her email rdbaconguis@up.edu.ph.

Conflict of Interest: Paul Jersey G. Leron and Rowena DT. Baconguis declare that they have no conflict of interest in this research and in this publication. The authors declare that they have no known competing financial interests or personal relationships that could have appeared to influence the work reported in this paper.

CONTRIBUTION INFORMATION

Accepting Editor: Les Labuschagne.| Received: 28-05-21 | Revised: 30-08-21| Accepted: 0109-21. Cite as: Leron PJ, Baconguis, RDT. 2021. Exploring the Dimensions of Innovation Culture in the Public Higher Education Institutions: Towards Improved Organizational Performance in Research and Development. Journal of Research Management and Administration. 1:1, 36-57.

(CC BY-NC 4.0) This article is licensed to you under a Creative Commons AttributionNonCommercial 4.0 International License. When you copy and redistribute this paper in full or in part, you need to provide proper attribution to it to ensure that others can later locate this work (and to ensure that others do not accuse you of plagiarism). You may (and we encourage you to) adapt, remix, transform, and build upon the material for any noncommercial purposes. This license does not permit you to use this material for commercial purposes. 